\title{
Evaluation of the National Oceanic and Atmospheric Administration/ Coupled-Ocean Atmospheric Response Experiment (NOAA/COARE) air-sea gas transfer parameterization using GasEx data
}

\author{
Jeffrey E. Hare, ${ }^{1,2}$ Christopher W. Fairall, ${ }^{3}$ Wade R. McGillis, ${ }^{4}$ James B. Edson, ${ }^{4}$ \\ Brian Ward, ${ }^{4}$ and Rik Wanninkhof ${ }^{5}$ \\ Received 19 February 2003; revised 21 July 2003; accepted 9 December 2003; published 16 July 2004.
}

[1] During the two recent GasEx field experiments, direct covariance measurements of air-sea carbon dioxide fluxes were obtained over the open ocean. Concurrently, the National Oceanic and Atmospheric Administration/Coupled-Ocean Atmospheric Response Experiment air-sea gas transfer parameterization was developed to predict gas transfer velocities from measurements of the bulk state of the sea surface and atmosphere. The model output is combined with measurements of the mean air and sea surface carbon dioxide fugacities to provide estimates of the air-sea $\mathrm{CO}_{2}$ flux, and the model is then tuned to the GasEx-1998 data set. Because of differences in the local environment and possibly because of weaknesses in the model, some discrepancies are observed between the predicted fluxes from the GasEx-1998 and GasEx-2001 cases. To provide an estimate of the contribution to the air-sea flux of gas due to wave-breaking processes, the whitecap and bubble parameterizations are removed from the model output. These results show that moderate (approximately $15 \mathrm{~m} \mathrm{~s}^{-1}$ ) wind speed breaking wave gas transfer processes account for a fourfold increase in the flux over the modeled interfacial processes. INDEX TERMS: 4504 Oceanography: Physical: Air/sea interactions (0312); 3339 Meteorology and Atmospheric Dynamics: Ocean/atmosphere interactions $(0312,4504) ; 0312$ Atmospheric Composition and Structure: Air/ sea constituent fluxes $(3339,4504) ; 3307$ Meteorology and Atmospheric Dynamics: Boundary layer processes; 4247 Oceanography: General: Marine meteorology; KEYWORDS: air-sea interaction, air-sea flux, air-gas transfer

Citation: Hare, J. E., C. W. Fairall, W. R. McGillis, J. B. Edson, B. Ward, and R. Wanninkhof (2004), Evaluation of the National Oceanic and Atmospheric Administration/Coupled-Ocean Atmospheric Response Experiment (NOAA/COARE) air-sea gas transfer parameterization using GasEx data, J. Geophys. Res., 109, C08S11, doi:10.1029/2003JC001831.

\section{Introduction}

[2] The air-sea exchange of climate relevant compounds and, in particular, carbon dioxide has come under increased scrutiny because of the continued uncertainty surrounding the mass sequestration of climate relevant compounds into the world's oceans and because of the potential consequence of atmospheric increases of these compounds on the Earth's climate. Mesoscale and larger-scale models could potentially supply reasonable regional- to global-scale estimations of the total gas transfer, provided that an accurate small-scale parameterization of the interfacial gas flux is incorporated.

\footnotetext{
${ }^{1}$ Cooperative Institute for Research in Environmental Sciences (CIRES), University of Colorado, Boulder, Colorado, USA.

${ }^{2}$ Also at NOAA Environmental Technology Laboratory, Boulder, Colorado, USA.

${ }^{3}$ Clouds, Radiation, and Surface Processes Division, NOAA Environmental Technology Laboratory, Boulder, Colorado, USA.

${ }^{4}$ Department of Applied Ocean Physics and Engineering, Woods Hole Oceanographic Institution, Woods Hole, Massachusetts, USA.

${ }^{5}$ Ocean Chemistry Division, NOAA Atlantic Oceanographic and Meteorological Laboratory, Miami, Florida, USA.
}

Copyright 2004 by the American Geophysical Union. 0148-0227/04/2003JC001831\$09.00
Focused surface process studies of gas transfer over the open ocean hold promise to provide information that can be used to improve the gas transfer parameterizations. Although techniques are improving, comprehensive open ocean measurement of the air-sea carbon dioxide flux and of the processes relevant to gas transfer present significant difficulties for measurements made from a ship.

[3] An ideal parameterization would accurately incorporate all of the physical mechanisms of gas transfer, including surface processes (influence of waves, microscale and larger-scale wave breaking, interfacial thermal structure, etc), subsurface processes (bubbles and turbulent mixing), micrometeorological influences (atmospheric surface layer turbulent structure, wind gustiness, etc), and would also account for chemical and marine biological sources and sinks. Much of the physics of gas exchange and the relative importance of each physical process remain largely unknown. However, it is imperative that progress in the development of accurate gas transfer parameterizations and in the continued improvement of measurement technology proceed in parallel. Of particular importance to gas exchange is the relative contribution of the globally averaged flux that occurs at relatively higher wind speeds. Because of wave-breaking and bubble mediation processes, 
gas transfer may be significantly enhanced in these regimes, yet direct field observations are nearly nonexistent.

[4] Before the advent of direct measurement of air-sea gas fluxes, the simple bulk relationship most commonly used in numerical models was of the form:

$$
F=V_{t} \Delta X
$$

where $\boldsymbol{F}$ represents the flux, $\boldsymbol{V}_{\boldsymbol{t}}$ is the gas transfer velocity (typically derived empirically), and $\Delta \boldsymbol{X}$ is the sea-air concentration difference. The first estimates of the transfer velocity were obtained from wind-water tank studies [e.g., Kanwisher, 1963; Liss and Merlivat, 1986] and global isotopic distributions [Broecker and Peng, 1974]. Although these pioneering studies advanced our understanding of the processes controlling air-water gas exchange, there persists a need to develop a parameterization that captures all of the relevant physical processes in open ocean gas transfer and also accurately represents the timescale of the forcing mechanisms.

[5] Research has firmly established that the air-sea gas transfer velocity (and therefore the gas flux) is a function of wind speed [Broecker et al., 1986; Jähne et al., 1987], but the numerous conflicting empirical relationships have triggered controversy over the years [Wanninkhof, 1992; Smith and Jones, 1985; Liss and Merlivat, 1986]. This problem has persisted, although recent developments have begun to reconcile our understanding of the relationship between wind speed and gas transfer [McGillis et al., 2001a]. However, because of the difficulties of making measurements in the open ocean [Fairall et al., 2000], there is a dearth of data at moderate to high wind speeds, where it is expected that a significant portion of the gas exchange takes place [Wanninkhof and McGillis, 1999; Spillane et al., 1986]. For example, during GasEx-1998, winds up to $17 \mathrm{~m} \mathrm{~s}^{-1}$ were recorded, but only for brief periods [McGillis et al., 2001a].

[6] Despite the paucity of direct gas flux observations in moderate to high wind speeds, there is a considerable theoretical basis for parameterizing gas flux in this regime. Air-entraining surface wave breaking is initiated at about 6-7 $\mathrm{m} \mathrm{s}^{-1}$ [O'Muircheartaigh and Monahan, 1986]. This process affects the surface roughness and introduces bubbles into the ocean mixed layer, thereby locally bypassing the direct interfacial gas exchange. These effects may dramatically increase the air-sea gas transfer. An additional contribution arises from enhanced turbulence beneath the breakers. For example, Terray et al. [1996] observed significant enhancement of turbulent dissipation in the presence of breaking waves. This effect is also expected to increase the gas flux, but a lack of near-surface ocean observations impedes our understanding of the physical processes. Some insights into gas transfer in the presence of breaking waves have been gleaned from laboratory studies [Asher and Wanninkhof, 1998], but there are significant scaling problems that prevent direct translation of the empirical results into geophysical scales.

[7] Because of the uncertainty surrounding gas transfer physics and the lack of observations, climate models employ a wide variety of transfer velocity parameterizations, which leads to significant ambiguity for estimates of the globally integrated carbon dioxide sequestration. For exam- ple, using a Weibul global wind distribution, a simple comparison of the Wanninkhof and McGillis [1999] cubic relationship to the Wanninkhof [1992] quadratic relationship yields a near doubling of the globally integrated annual flux of $\mathrm{CO}_{2}$ into the ocean. This difference will have severe consequences in long-term climate model estimates of the thermal influence of climate relevant compounds in the atmosphere.

[8] In section 2, we will briefly describe the GasEx set of experiments, and the measurements that were used in the evaluation herein. Section 3 contains a brief description of the National Oceanic and Atmospheric Administration/ Coupled-Ocean Atmospheric Response Experiment (NOAA/COARE) gas flux parameterization, while more attention is given to the specifics of the computation of the gas flux in section 4. In section 5, we present the results of the application of the parameterization to the GasEx data sets, and we compare the output of the parameterized gas fluxes to the direct covariance flux measurements. Finally, a brief conclusion is provided in section 6 .

\section{GasEx Experiments}

[9] In 1998, the Ocean-Atmosphere Carbon Exchange Study (OACES) program (now part of the Global Carbon Cycle program) of the NOAA Office of Global Programs (OGP) initiated a program of process studies intended to improve our understanding of air-sea gas flux processes. These investigations were designed to make observations of gas fluxes and gas transfer forcing mechanisms on relatively short timescales ( 1 hour) with the goal to quantify gas transfer velocities through improved parameterizations.

[10] The first deployment occurred onboard the NOAA ship Ronald H. Brown in May and June 1998. This multiinstitutional, interdisciplinary air-sea experiment was named GasEx-1998. The primary study occurred in the North Atlantic in a warm-core eddy near $46^{\circ} \mathrm{N}, 21^{\circ} \mathrm{W}$, and this locale was specifically selected to provide a stable laboratory for injection of deliberate tracers and for maximization of $\mathrm{CO}_{2}$ transfer signal levels. Current gas instrumentation technology limits our ability to detect carbon dioxide fluctuations associated with transfer processes except in the largest source or sink regimes. The stability of the eddy and the presence of an algal bloom led to significant atmospheric signal levels of carbon dioxide over the course of the main experiment, with a mean value of the airsea partial pressure gradient, $\Delta \mathrm{pCO}_{2}$, of approximately $-85 \mu \mathrm{atm}$. More details are given by McGillis et al. [2001a, 2001b].

[11] During GasEx-1998, a modified fast response, closed path, nondispersive infrared (NDIR) $\mathrm{CO}_{2} / \mathrm{H}_{2} \mathrm{O}$ gas analyzer was deployed on the ship to continuously measure atmospheric carbon dioxide and water vapor fluctuations. When combined with motion-corrected sonic anemometer measurements of local fluctuations of the vertical wind velocity, $\boldsymbol{w}^{\prime}$ [Edson et al., 1998], direct covariance estimates of the air-sea flux of carbon dioxide were obtained as in:

$$
\boldsymbol{F}=\overline{\boldsymbol{w}^{\prime} \boldsymbol{c}^{\prime}}
$$

where the overbar denotes a time average, and $\boldsymbol{w}^{\prime}$ and $\boldsymbol{c}^{\prime}$ are the fluctuations of vertical velocity and gas concen- 
tration, respectively. Additional instruments deployed on the ship were used to make measurements of the local mean meteorological and surface conditions: air temperature and humidity, sea surface temperature, downwelling solar and infrared radiative flux, cloud base height, and atmospheric boundary layer profiles of temperature, humidity, and wind. Continuous samples of atmospheric and oceanic concentrations of $\mathrm{CO}_{2}$ were made with the permanent NOAA Atlantic Oceanic and Meteorological Laboratory (AOML) system on the ship.

[12] On the basis of the success of the first GasEx cruise [McGillis et al., 2001a, 2001b], another surface processes and gas flux campaign was scheduled for February 2001. This cruise also took place on the NOAA ship Ronald $H$. Brown and was named GasEx-2001. In contrast to the first GasEx-1998 cruise, this expedition was primarily located in the eastern Pacific, just south of the equatorial Pacific upwelling region. Complex processes and iron deficiency limit the biological productivity in this region [Strutton et al., 2004], so this region is a relatively strong source of $\mathrm{CO}_{2}$ into the atmosphere. The average $\Delta \mathrm{pCO}_{2}$ for GasEx2001 was approximately $+110 \mu \mathrm{atm}$, with a characteristic diurnal cycling of about $5 \mu \mathrm{atm}$. On the basis of measurements of the local microlayer, little biological activity was detected at the sea surface [Nelson Frew, WHOI personal communication].

[13] As in the first GasEx cruise, an improved closed path NDIR system was deployed to measure the fluctuations of $\mathrm{CO}_{2}$ in order to compute the direct covariance flux. The mean meteorological and $\mathrm{CO}_{2}$ measurements were essentially the same for the second deployment, with the addition of measurements of the underlying waves and atmospheric boundary layer wind profiles from the permanent $915 \mathrm{MHz}$ radar system [Law et al., 2002]. The wind profiler and ceilometer measurements confirmed that the mesoscale meteorological conditions during the course of the experiment were very steady, with very little variability in boundary layer structure.

\section{NOAA/COARE Air-Sea Gas Flux Parameterization}

[14] Recently, Fairall et al. [2000] presented a gas transfer parameterization, which is based on the wellknown COARE Bulk Flux Algorithm [Fairall et al., 1996b] with the addition of surface renewal concepts from Soloviev and Schlüssel [1994]. The original COARE model contains an algorithm for the oceanic cool skin, which has been generalized for gas transfer applications. A full presentation of the development of the NOAA/ COARE gas flux parameterization, in addition to relevant background information on the history of gas transfer parameterization and micrometeorological measurement techniques are given by Fairall et al. [2000]. Ideally, a physically based air-sea gas transfer parameterization will require reasonably available variables as inputs. That is, the algorithm should only require input variables that can be readily measured over the relevant driving scales from in situ or remote sensors. In addition, the parameterization should compute the gas transfer velocity within the context and timescale of the relevant environmental variables and processes (radiative and turbulent fluxes, wind speed, wave state, surface current, air-sea temperature difference, near-surface water thermal structure, etc). Fairall et al. [2000] present one such micrometeorologically based air-sea gas transfer parameterization.

[15] The parameterization relies on matching of the water and air flux expressions (both of which are expressed in terms of molecular and turbulent components), in addition to attending to the details of the molecular layer transfer on the water side. The final expression is quite general, and can be applied to any gas:

$$
\boldsymbol{F} \boldsymbol{s}=\frac{\boldsymbol{A}_{\boldsymbol{s o l}} \boldsymbol{u}_{* a} \Delta p \boldsymbol{x}}{\sqrt{\rho \boldsymbol{w} / \rho \boldsymbol{a}}\left[\boldsymbol{h w} \boldsymbol{S}_{c \boldsymbol{w}}^{1 / 2}+\ln (\boldsymbol{z w} / \delta \boldsymbol{w}) / \kappa\right]+\alpha\left[\boldsymbol{h a} \boldsymbol{S}_{c a}^{1 / 2}+\boldsymbol{C}_{\boldsymbol{d}}^{1 / 2}-5+\ln \left(\boldsymbol{S}_{c a}\right) /(2 \kappa)\right]},
$$

where the subscripts $\boldsymbol{s}, \boldsymbol{a}$, and $\boldsymbol{w}$ denote the surface, air, and water, $\alpha$ is the dimensionless solubility (a function of species, temperature, and salinity), $\boldsymbol{u}_{*_{\boldsymbol{a}}}$ is the air-side friction velocity, $\boldsymbol{\Delta} \boldsymbol{p}$ is the partial pressure difference of the gas (species subscript $\boldsymbol{x}$ ) across the air-sea interface, $\boldsymbol{\rho}$ is the density, $\boldsymbol{S}_{\boldsymbol{c}}$ is the Schmidt number of the gas, $\boldsymbol{z}$ is the depth of the measurement, $\delta$ is the estimated turbulent surface layer thickness, $\kappa$ is the von Kármán constant, and $\boldsymbol{C}_{\boldsymbol{d}}$ is the atmospheric velocity drag coefficient. In addition, in equation (3) the solubility has been expressed as

$$
\boldsymbol{A}_{\text {sol }}=10^{5} \alpha /\left(\boldsymbol{R}_{\text {gas }} \boldsymbol{T}\right)
$$

where $\boldsymbol{T}$ is the temperature, $\boldsymbol{R}_{\text {gas }}$ is the universal gas constant, and

$$
\boldsymbol{h}=\frac{\Lambda \boldsymbol{R}_{r}^{1 / 4}}{\varphi}
$$

where $\boldsymbol{\Lambda}$ is an adjustable constant, $\boldsymbol{R}_{\boldsymbol{r}}$ is the roughness Reynolds number, and $\varphi$ is an empirical function that accounts for buoyancy effects on turbulent transfer in the ocean. Most of the computed variables in equation (3) are estimated from the NOAA/COARE algorithm, given the input of air and sea temperature, wind speed, specific humidity, salinity, downwelling shortwave and longwave radiation, rain rate, atmospheric pressure, and measurement heights and water depth. Details on the computation of these variables are given by Fairall et al. [1996b, 2000]. In fact, the practical calculation from equation (3) can be isolated to estimate the solubility times gas transfer velocity $\left(\boldsymbol{\alpha} \boldsymbol{k}_{\boldsymbol{c o} 2}\right)$ by dividing both sides of the equation by the partial pressure difference. This information $\left(\Delta \boldsymbol{p}_{\boldsymbol{x}}\right)$ can be obtained from the current generation of continuous underway air and sea $\mathrm{CO}_{2}$ measurement systems on ships [Wanninkhof and Thoning, 1993]. Thus the NOAA/COARE gas flux parameterization provides a description of the physical environs, and we require an external estimate of the gas mass differential across the interface in order to arrive at the gas flux.

[16] A number of possible sea 'surface' temperatures inputs exist: subsurface $(3-5 \mathrm{~m})$ water intake temperature from the ship thermosalinigraph, the near-surface temperature measured from a floating thermistor (or modeled from the $5 \mathrm{~m}$ temperature), or a radiometrically measured skin temperature [Ward et al., 2004]. The molecular 
conditions near the interface, including the interfacial skin temperature, control the mass flux. The cool skin has a temperature that is primarily controlled by evaporation and net longwave radiative cooling, and its depth is confined to the molecular diffusive sublayer in the water. Below this depth, there may occur a warm layer whose structure is determined by the balance of solar warming of the upper ocean and mixing processes. Deep, strong gradient warm layers tend to occur in light wind conditions. If measurements of the true interfacial temperature are not available, then the use of any other measured temperature as input to the bulk algorithm requires a model of the thermal structure up to the skin surface [Fairall et al., 1996b].

[17] The NOAA/COARE air-sea bulk gas transfer parameterization makes use of turbulence scaling theory applied to both fluids, and matches the fluid models at the interface where the suppression of the smallest turbulent eddies is accomplished via viscous dissipation. Bubble mediation and wave breaking have only been addressed in the model in a heuristic fashion because of the complex nature of these physical forcings. Given the lack of scientific consensus on this issue, we have simply chosen an additive bubble and wave-breaking enhancement for the gas transfer velocity [Woolf, 1997]:

$$
\boldsymbol{k}_{\boldsymbol{b}}=\boldsymbol{V} \boldsymbol{f} \alpha^{-1}\left[1+\left(\boldsymbol{e} \alpha \boldsymbol{S}_{c}^{-1 / 2}\right)^{-1 / \boldsymbol{n}}\right]^{-\boldsymbol{n}}
$$

where $\boldsymbol{V}, \boldsymbol{e}$, and $\boldsymbol{n}$ are constants, and the whitecap fraction, $\boldsymbol{f}$, from Monahan and O'Muircheartaigh [1980], is given by

$$
\boldsymbol{f}=\boldsymbol{B} \boldsymbol{U}^{3.4}
$$

where $\boldsymbol{U}$ is the mean wind speed and $\boldsymbol{B}$ is an empirical constant. This higher wind enhancement of the transfer velocity in equation (6) is added to the transfer velocity, $\boldsymbol{k}_{\boldsymbol{c o} 2}$, derived from equation (3) to establish the combined effect of interfacial and breaking wave processes.

\section{Gas Flux}

[18] The expression in equation (3) of the air-sea flux of carbon dioxide (or any gas) can be written as

$$
\boldsymbol{F}=\boldsymbol{k} \alpha\left(\boldsymbol{f C \boldsymbol { O } _ { 2 w }}-\boldsymbol{f C} \boldsymbol{O}_{2 a}\right)
$$

where $\boldsymbol{k}$ is the gas transfer velocity (similar to $\boldsymbol{V}_{\boldsymbol{t}}$ in equation (1)), and $\mathrm{fCO}_{2}$ is the fugacity of carbon dioxide in the bulk water and ambient air, respectively. Practically, measurement of fugacity at the air-sea interface is not possible, so water is drawn in situ from the 'bulk surface' water at depths between $1-5 \mathrm{~m}$. The solubility is a function of both temperature and salinity and can be empirically described such as by Wanninkhof [1992, Table A2]. The solubility for $\mathrm{CO}_{2}$ varies by a few percent per degree around $20^{\circ} \mathrm{C}$ [Weiss, 1974]. The gas transfer velocity can be conceptualized as related to the traditional transfer coefficients in bulk turbulent flux parameterizations. This quantity has recently been expressed as a quadratic and cubic function of wind speed $(\boldsymbol{U})$ in Wanninkhof [1992] and
Wanninkhof and McGillis [1999], respectively, and it also has a Schmidt number dependence:

$$
\boldsymbol{k}=\boldsymbol{k}\left(\boldsymbol{S} \boldsymbol{c}^{-\boldsymbol{n}}, \boldsymbol{U}^{\boldsymbol{m}}\right),
$$

where $\boldsymbol{n}$ varies from 0.67 for a smooth surface to 0.4 for a surface characterized with bubbles, and $\boldsymbol{m}$ has been empirically determined to be between 2 and 3 for field data.

[19] In most ship-based situations, the water-side $\mathrm{CO}_{2}$ mixing ratio is measured by drawing continuous bulk (subscript $\boldsymbol{w}$ ) water samples into a headspace equilibrator [Wanninkhof and Thoning, 1993]. Typically, this sample comes from a water intake in the forward hull of the ship at a depth of 3-5 m. The air-side sample (from a height of approximately $10 \mathrm{~m}$ ) and headspace carbon dioxide mixing ratios are determined with an NDIR detector, and the results are converted to fugacity. Given direct measurement of the gas flux [McGillis et al., 2001a] coincident with air and sea gas mixing ratio measurements, one can use equation (8) to determine the gas transfer velocity. This quantity has been used to develop simplified wind speed-dependent gas exchange models [Wanninkhof and McGillis, 1999].

[20] Upon closer inspection, the flux is more accurately expressed in terms of the bulk and interfacial solubilities as in

$$
\boldsymbol{F}=\boldsymbol{k}_{\boldsymbol{s}}\left(\alpha_{w} \boldsymbol{f} \boldsymbol{C} \boldsymbol{O}_{2 w}-\alpha_{\mathbf{s}} \boldsymbol{f} \boldsymbol{C} \boldsymbol{O}_{2 a}\right),
$$

where the subscript $\boldsymbol{s}$ indicates that the transfer velocity and solubility are computed at the skin temperature and salinity. The expression in equation (10) assumes that mass is conserved (i.e., $\boldsymbol{\alpha}_{w} f \boldsymbol{C} \boldsymbol{O}_{2 w}$ is conserved with depth), which is a simplification assuming no biological effects [Ward et al., 2004]. In fact, this expression ignores the warm layer effect in the ocean [Fairall et al., 1996a], while we require that the water-side fugacity and solubility be computed at the surface, since the interfacial characteristics so strongly affect the gas flux. For example, cool skin temperature depression typically ranges from 0.1 to 0.4 degrees [Fairall et al., 1996a], and warm layer elevation under light winds can be as large as $2^{\circ}-3^{\circ}$ in the tropics. This thermal structure from the bulk water up to the surface will certainly alter the flux. For the sake of physical accuracy in the parameterization, we will express the flux in terms of the interfacial characteristics.

[21] There are other thermal influences on the flux of the gas, including the effect of the warm layer (and/or cool skin) on the fugacity of $\mathrm{CO}_{2}$ dissolved in seawater [Takahashi et al., 1993] via the carbonate reaction. This requires a deviation from the mass conservation assumption, so the surface fugacity is expressed in terms of the bulk water fugacity through an empirical relationship:

$$
\boldsymbol{f C \boldsymbol { O } _ { 2 s }}=\boldsymbol{f} \boldsymbol{C} \boldsymbol{O}_{2 w}(1+0.0423 \Delta \boldsymbol{T}),
$$

where $\Delta \boldsymbol{T}=\boldsymbol{T}_{\boldsymbol{w}}-\boldsymbol{T}_{\boldsymbol{s}}$. The small percentage change with temperature was determined at a reference temperature of $20^{\circ} \mathrm{C}$, and it also includes the effect of solubility changes with temperature. A quick computation of the solubility at $20^{\circ} \mathrm{C}$ reveals that the effect of temperature alone on solubility accounts for approximately $2.7 \%$ of the total change in fugacity. Therefore the remaining $1.5 \%$ change in 
fugacity of carbon dioxide due to a temperature difference between the bulk water and the interfacial surface comes from the change in mass due to reaction. We have chosen to maintain the structure of our expression of the flux as in equation (10) with the addition of the small temperature correction to the mass due to the carbonate reaction as follows:

$$
\boldsymbol{F}=\boldsymbol{k}_{\boldsymbol{s}} \alpha_{\boldsymbol{s}}\left[\boldsymbol{f} \boldsymbol{C} \boldsymbol{O}_{2 \boldsymbol{w}} \frac{\alpha_{\mathrm{w}}}{\alpha_{\mathrm{s}}}(1+0.015 \Delta \boldsymbol{T})-\boldsymbol{f} \boldsymbol{C} \boldsymbol{O}_{2 \boldsymbol{a}}\right],
$$

Here, $\boldsymbol{\alpha}_{w}$ and $\boldsymbol{\alpha}_{\boldsymbol{s}}$ are evaluated at temperatures $\boldsymbol{T}_{\boldsymbol{w}}$ and $\boldsymbol{T}_{\boldsymbol{s}}$, respectively.

[22] This expression is more accurate than equation (8) and provides a statement of the flux in terms of the measured fugacities and bulk water temperature, along with the estimate of skin temperature. The NOAA/COARE algorithm models the skin temperature by combining both the cool skin and warm layer algorithms applied to measurements within or below the warm layer from which the surface solubility can be computed. For the GasEx data sets, the error represented by calculation of the flux using equation (10) instead of the more accurate equation (12) is at most a few percent [Hare et al., 2003]. However, under circumstances of strong cool skin and warm layer development, the necessity of computing the flux from equation (12) becomes more imperative.

[23] From Soloviev and Schlüssel [1994], the water-side component of equation (5) is modified to the expression

$$
h \boldsymbol{w}=\frac{\Lambda \boldsymbol{R}_{r}^{1 / 4}}{A \varphi x}
$$

where $\varphi_{x}$ is a function providing for buoyancy effects [Fairall et al., 2000], $\boldsymbol{\Lambda}$ is the cool skin adjustment constant equal to 13.3, and $\boldsymbol{A}$ has a value of 1.85 [Soloviev and Schlüssel, 1994] based on a supersaturated radon data set. The NOAA/COARE parameterization also allows for the substitution of the COARE cool-skin algorithm to characterize the surface, but the physics are essentially the same. In the COARE model, the cool skin constant has been empirically found to be 15.8 . The difference between the Soloviev and Schlüssel [1994] and Fairall et al. [2000] constants will play a part in the gas transfer parameterization of the two GasEx data sets in section 5 .

[24] Alternatively, the algorithm allows for input of direct measurement of the radiometric (skin) temperature, if it is available. In addition, the algorithm models the depth of the warm layer, which can be used to determine whether the fugacity measurement has been made within or below the layer. It is necessary to add a thermal correction to the measurements in the conversion from mole fraction to fugacity [Ward et al., 2004], but we will not include those details here.

[25] The current version of the NOAA/COARE gas flux parameterization also provides an estimate of the surface gas transfer velocity expressed as the sum of the influential physical resistances, which include the molecular and turbulent components on both sides of the interface. An additional transfer velocity term arises under higher wind regimes as a result of bubble mediation and wave breaking and is expressed in equation (6). No considerations are given to the effect of biological processes or to surfactants, although these environmental forcings are recognized to be potentially significant [Frew, 1997].

\section{Application of the Parameterization}

[26] The NOAA/COARE gas transfer parameterization has been evaluated using data collected during the GasEx1998 and GasEx-2001 experiments (see section 2). These data include directly measured carbon dioxide fluxes, mean meteorological and surface observations, and water and air $\mathrm{CO}_{2}$ fugacities. Standard procedures were used to exclude data from undesirable relative wind directions, during ship maneuvers or rain, for occasional poor motion corrections or abnormal values in the observations, etc. We then input the resulting $10 \mathrm{~min}$ averaged data into the NOAA/COARE routine, and after tuning the model to the GasEx-1998 data set, we are able to evaluate the resulting balance between interfacial and breaking wave processes at higher winds. In addition, a comparison of the parameterized transfer velocities from the two GasEx data sets will shed some light into the model's weaknesses.

[27] We know of no other gas transfer model which incorporates the level of detailed physics which is included in the NOAA/COARE parameterization. Nevertheless, we realize that not all of the complex interfacial processes are adequately represented in the model. For example, the bubble contribution to the flux relies on a simple wind speed-dependent empirical formula, and there are no provisions in the model for the effects of biological processes. In the following sections, we will examine some of the deficiencies of the NOAA/COARE parameterization in order to highlight areas for future improvement. Then, we will demonstrate the effect that wave-breaking and bubble processes have on the gas flux through an analysis of the interfacial component of the parameterization and the directly measured GasEx-1998 fluxes. Finally, we will examine the overall error in the measured and parameterized results by compositing the GasEx results in terms of the interfacial fugacity discontinuity. This analysis also includes data from very low flux regimes obtained during the 1999 season in the western Pacific.

\subsection{GasEx Parameterizations}

[28] Initially, $\boldsymbol{A}$ in equation (13) and $\boldsymbol{V}$ in equation (6) were tuned to the GasEx-1998 flux results. We chose to adjust these coefficients to the GasEx-1998 data set because of the wide range of wind speeds observed during this cruise compared to that of the GasEx-2001 expedition. The fit to the data requires adjustment of the two coefficients $(\boldsymbol{A}=0.625$ and $\boldsymbol{V}=4900)$ which are significantly different than those provided from the original references (Soloviev and Schlüssel [1994], $\boldsymbol{A}=1.85$; and Woolf [1997], $\boldsymbol{V}=$ 2450).

[29] Given the circumstances, the modification of the high wind speed coefficient is not particularly alarming. In the case of the Woolf [1997] model, the coefficient, $\boldsymbol{V}$, was derived from an expression which was best fit to modeled bubble transfer velocities and was combined with statistical estimates of a wind speed-dependent model of whitecap coverage from photographic evidence [O'Muircheartaigh and Monahan, 1986]. Neither of these empirical expressions can be considered to be comprehensive, given the wide 

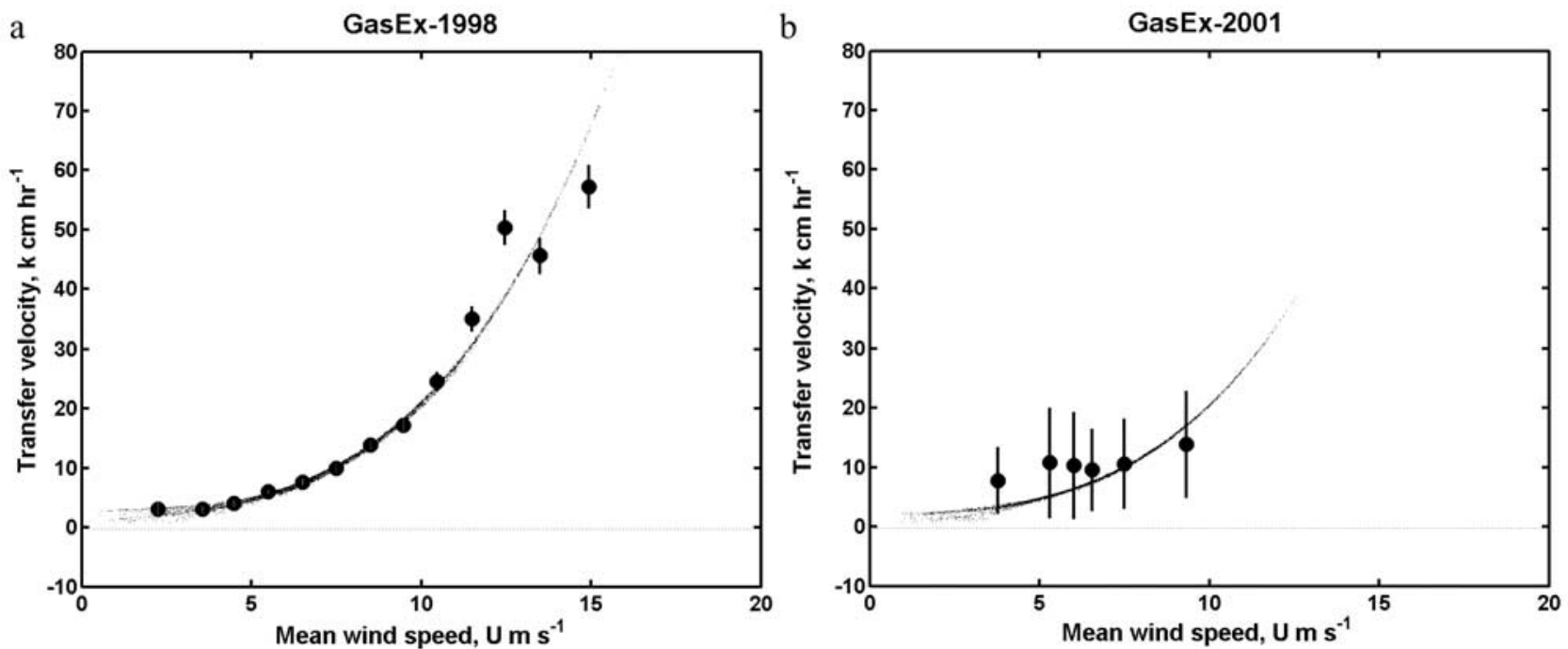

Figure 1. Modeled (small points) and measured (solid circles, from equation (12)) $\mathrm{CO}_{2}$ transfer velocity versus mean wind speed for (a) GasEx-1998 and (b) GasEx-2001. The NOAA/COARE gas transfer parameterization has been tuned for best fit to this data set.

range of wind, wave, and breaking conditions which could be encountered in the field. Furthermore, numerous simplifying assumptions have been made in the development of the Woolf [1997] and O'Muircheartaigh and Monahan [1986] expressions, which contribute to the considerable uncertainties which surround them.

[30] Moreover, the original low wind speed empirical constant, A, [Soloviev and Schlüssel, 1994, Figure 4] was obtained from a combination of data sets which displayed an admitted large degree of uncertainty. The radon field data used to infer their coefficient was obtained indirectly and had been integrated over several days of sampling with all environmental variability embedded within. Given that our parameterization was applied to 10 min mean samples, it is difficult to interpret the resulting adjustment to $\boldsymbol{A}$. Finally, it must be recognized that GasEx-1998 was conducted in a particular biological and physical field environment, which may or may not be considered to be representative of a typical gas transfer regime.

[31] Figure 1 shows the transfer velocity plotted versus mean wind speed for GasEx-1998 (Figure 1a) and GasEx2001 (Figure 1b). The small points are the optimized NOAA/COARE gas flux parameterization output from equation (3) including the enhanced transfer velocity contribution from equation (6), and the large solid circles are the bin-averaged transfer velocities computed from the actual $\mathrm{CO}_{2}$ flux and mean measurements and using equation (12). The small points demonstrate more scatter at low wind speeds, which indicates more sensitivity to buoyant processes than for those points at higher winds. From Figure 1a, reasonable agreement is seen between the model-derived transfer velocity and the actual measurements. This is not unexpected, since we have tuned the two model parameters for best agreement to the 1998 data set. However, an examination of the 2001 results (Figure 1b) shows some significant deviation between the NOAA/COARE parameterization output and the measurements, particularly for lower $\left(<6 \mathrm{~m} \mathrm{~s}^{-1}\right)$ winds. The range of wind speeds was limited during GasEx-2001, with the majority of the measured wind speeds between 4 and $7 \mathrm{~m} \mathrm{~s}^{-1}$. Fewer samples are available for winds above the threshold for wave breaking, so we cannot speculate on the significance of the higher wind speed bin model fit for the GasEx-2001 results.

[32] From Figure 1, we see relatively greater gas transfer at low wind speeds near the Equator (GasEx-2001). Some significant differences were observed between the two experimental locales, which might explain the inconsistent fit to the model. Significant biological activity was observed during GasEx-1998 (based on the measured flux of $\mathrm{CO} 2$ into the sea surface), while GasEx-2001 was in a regime of low biological productivity [Strutton et al., 2004]. In addition, GasEx-2001 took place in the Equatorial current, where shear mechanics and diurnal cycling force variability of the ocean mixed layer depth between 2 and $20 \mathrm{~m}$ (W. McGillis et al., Air-sea $\mathrm{CO}_{2}$ exchange in the equatorial Pacific, submitted to Journal of Geophysical Research, 2004). In contrast, GasEx-1998 occurred in a midlatitude stable warm-core eddy with little diurnal variability. Significant mixing occurred as a result of changes in wind speed throughout the course of the GasEx-1998 experiment [McGillis et al., 2001a]. The NOAA/COARE parameterization characterizes the gas transfer from the mixed layer through standard Monin-Obukhov similarity (MOS), which works well on the air side but is oversimplified for the ocean. This lack of detail may contribute to discrepancy between the 1998 and 2001 results.

[33] A subsequent analysis reveals that a best fit of the parameterization to the relatively low wind observed flux data of GasEx-2001 requires the constant $\boldsymbol{A}$ to have a value of approximately 1.5 (not shown), which is much closer to the value surmised by Soloviev and Schlüssel [1994]. It must be noted that the error bars on the GasEx-2001 transfer velocity estimates are larger, and this can be seen from a comparison of Figures $1 \mathrm{a}$ and $1 \mathrm{~b}$. The fact that the coefficient, $\boldsymbol{A}$, requires readjustment to fit the GasEx-2001 data highlights the significant uncertainty still inherent in the 


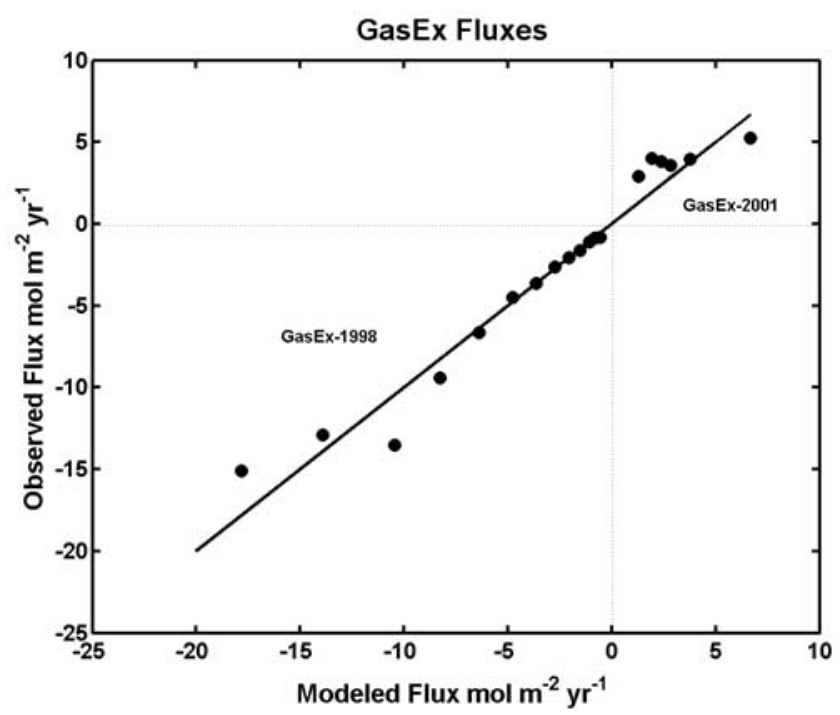

Figure 2. Modeled (solid line) and directly measured (solid circles) $\mathrm{CO}_{2}$ fluxes from both GasEx experiments plotted versus the modeled flux.

parameterization of the transfer velocity and underlines the need for more comprehensive experimental examination of the factors which influence gas transfer at all wind speeds.

[34] For example, the NOAA/COARE algorithm assumes that all of the wind stress goes into production of mechanical turbulence in the water-side mixed layer. That is, expression:

$$
\rho_{\boldsymbol{a}} \boldsymbol{u}_{*_{\boldsymbol{a}}}^{2}=\rho_{\boldsymbol{w}} \boldsymbol{u}_{*_{w}}^{2}
$$

This is a simplification, as a portion of the wind energy is recognized to be transferred into the production and growth of waves as well as into driving the surface current. Furthermore, there is a reasonable expectation that the pressure field is modified in the presence of the surface wave field [Janssen, 1999] and that breaking waves are responsible for enhanced subsurface turbulent energy dissipation [Terray et al., 1996]. Both of these processes modify the balance of terms in the turbulent kinetic energy equation, and this modification of the near surface physics may create a situation in which the departure from MOS is a source of error in the model. However, these departures would be most influential in the moderate and high wind speed regimes.

[35] The fine-scale thermal structure of the water column is complicated by biological activity, cool skin and warm layer dynamics, and currents. The thermal profile from the depth of gas measurement at $5 \mathrm{~m}$ up to the surface will affect the resulting $\mathrm{CO}_{2}$ fugacity at the interface and will contribute to the buoyant production of turbulent energy in the water. All of these effects contributed to the oceanic thermal structure to various degrees during the GasEx cruises, but few comparable direct measurements were obtained for both experiments. Given that the thermal structure and biological activity are most influential to the gas flux in lighter wind situations, we surmise that these processes are the cause of the bias seen between Figures 1a and 1b. The carbon dioxide flux during GasEx-1998 can be attributed to the biological productivity, although no direct productivity measurements were made during the cruise. In the case of Figure 1b, the lack of biological activity during GasEx-2001 contributes in the correct manner to the bias observed for the lower wind speeds.

[36] The surfactant levels present during GasEx-1998 and GasEx-2001 are likely to be the source of some of the disparity in the gas transfer values [Bock et al., 1999]. Microbial production in surface ocean water is a known source of colored dissolved organic matter (CDOM). Microbial production in the North Atlantic is higher than in the equatorial Pacific, and the CDOM levels are three times higher in the North Atlantic [Siegel et al., 2002]. This increase in CDOM and the corresponding increase in surface films could cause a factor of two decrease in gas exchange [Frew, 1997], which is consistent with the differences seen in Figures $1 \mathrm{a}$ and $1 \mathrm{~b}$.

[37] Figure 2 shows bin-averaged fluxes from both the NOAA/COARE parameterization (using equation (3)) and the directly measured covariance fluxes [McGillis et al., 2001a]. The solid 1:1 line is the modeled flux, and the large solid circles are the WHOI data. The ability of this model to represent the fluxes, at least in an averaged sense, is impressive for the GasEx-1998 data set. The GasEx-2001 parameterized results show somewhat more scatter, but the overall fit is reasonable.

\subsection{Whitecap Contribution}

[38] Figure 3 shows transfer velocity plotted against mean wind speed for both experiments, but with the bubble parameterization omitted $\left(\boldsymbol{k}_{\boldsymbol{b}}=0\right)$. This demonstration is enlightening, as it clearly shows the regime where bubbles and whitecap processes begin to affect the flux $\left(\boldsymbol{U}>6 \mathrm{~m} \mathrm{~s}^{-1}\right)$ and shows the relative contribution to the transfer velocity at higher wind speeds. Here, the contrast between GasEx-1998 and GasEx-2001 becomes more striking. The equatorial region is apparently characterized by much stronger direct interfacial transfer but smaller bubble mediated effects, relative to the GasEx-1998 results.

[39] Further enlightenment is gained by examination of the fluxes in Figure 4, where the wave-breaking and bubble parameterization has been set to zero. Significant differences are seen between the parameterized fluxes (solid 1:1 line) and the measured fluxes (large solid circles) except in the lightest wind cases (below about $2 \mathrm{~mol} \mathrm{~m}^{-2} \mathrm{yr}^{-1}$ ). The lack of relatively high wind speed gas fluxes in the GasEx2001 data set precludes making general statements about the universality of the breaking wave and bubble mediation enhancement of the fluxes. However, from the GasEx-1998 fluxes, we see that there is a factor of four enrichment of the $\mathrm{CO}_{2}$ transfer at approximately $15 \mathrm{~m} \mathrm{~s}^{-1}$. This represents a significant finding for the comparison of the interfacial wave-breaking processes represented by both the NOAA/ COARE gas flux parameterization and the directly measured fluxes from GasEx-1998. In addition, this observation highlights the need to improve air-sea gas flux parameterizations for the higher wind speeds.

[40] In Figure 5, we show the contribution to the air-sea gas flux from breaking wave processes alone. This estimate is obtained from the directly measured gas flux minus the interfacial flux, obtained from the parameterized transfer 
a

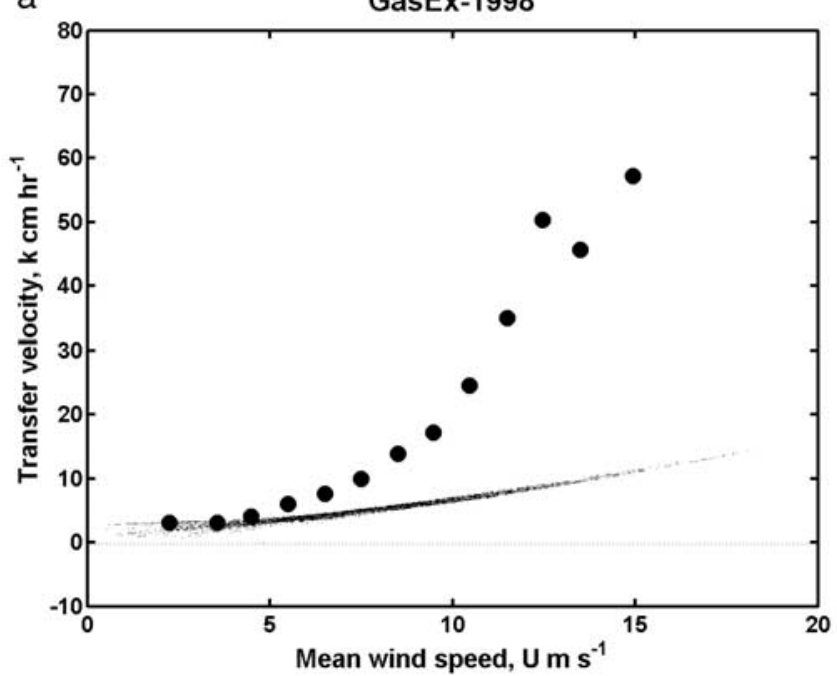

$\mathrm{b}$

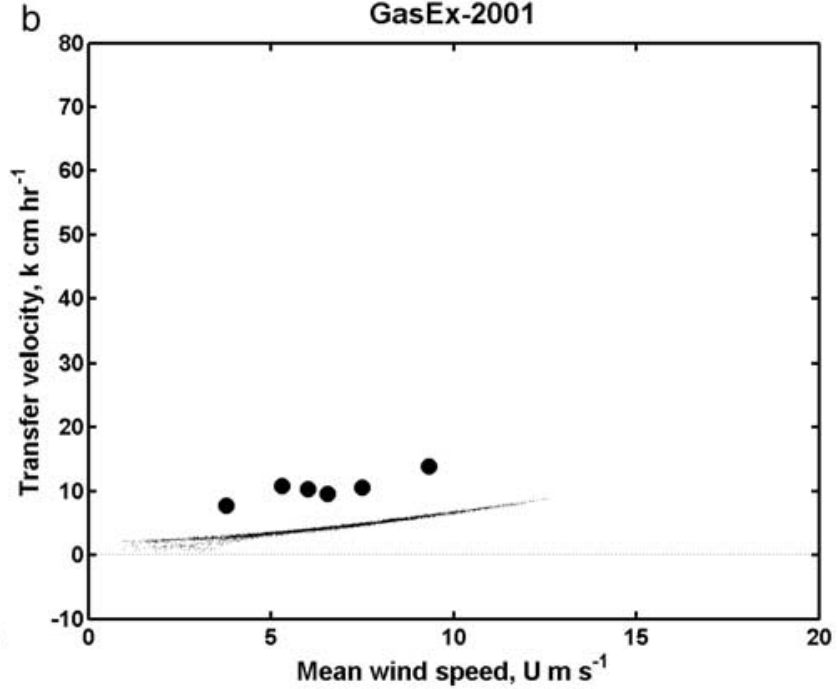

Figure 3. Modeled (small points) and measured (solid circles) $\mathrm{CO}_{2}$ transfer velocity versus mean wind speed for (a) GasEx-1998 and (b) GasEx-2001 with $\boldsymbol{k}_{\boldsymbol{b}}=0$ in equation (6).

velocity with the whitecap/bubble algorithm turned off $\left(\boldsymbol{k}_{\boldsymbol{b}}=0\right.$ in equation (6)). Here, we plainly see the impact of wave breaking to gas transfer, with more than $80 \%$ of the flux at $14 \mathrm{~m} \mathrm{~s}^{-1}$ coming from the breaking wave processes.

\subsection{Three Cruise Composite}

[41] In an effort to make improvements to the gas instrumentation and measurement methods and to gain experience with the system in a variety of environments, NOAA/ETL and WHOI collaborated to deploy the NDIR on the JASMINE and Nauru'99 cruises on the Ronald $H$. Brown from May to July of 1999. The ship track for these cruises ran from Singapore into the Indian Ocean, then down to Darwin Australia, through the Solomon Islands, and on to the island nation of Nauru at $0.32^{\circ} \mathrm{S}, 166.55^{\circ} \mathrm{E}$.

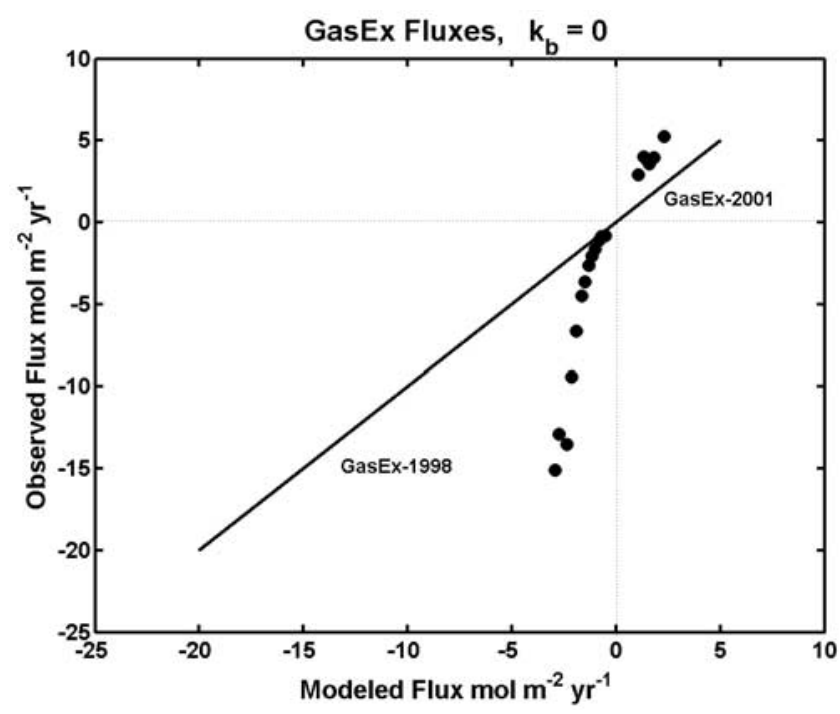

Figure 4. Modeled (solid line) and measured (solid circles) $\mathrm{CO}_{2}$ fluxes from both GasEx experiments with $\boldsymbol{k}_{\boldsymbol{b}}$ $=0$ in equation (6) plotted versus the modeled flux.
The gas flux measurement effort was made as an ancillary addition to the JASMINE and Nauru'99 objectives, and more information for these two cruise legs can be found at websites: http://paos.colorado.edu/ jasmine/ and http:// www.etl.noaa.gov/programs/1999/nauru99/.

[42] For the first time, the $\mathrm{CO}_{2}$ gas flux measurement system was operated in a very low flux regime, as the mean air-sea fugacity difference over the course of these cruises was approximately $10 \mu \mathrm{atm}$. This low signal presents significant challenges to the measurement of the carbon dioxide flux, and careful scrutiny of the resulting data set was required in order to obtain meaningful statistics. For example, the presence of any rainfall, traveling close to nearby islands, or modest ship motion produced unacceptable errors in the results. Using experience from GasEx-

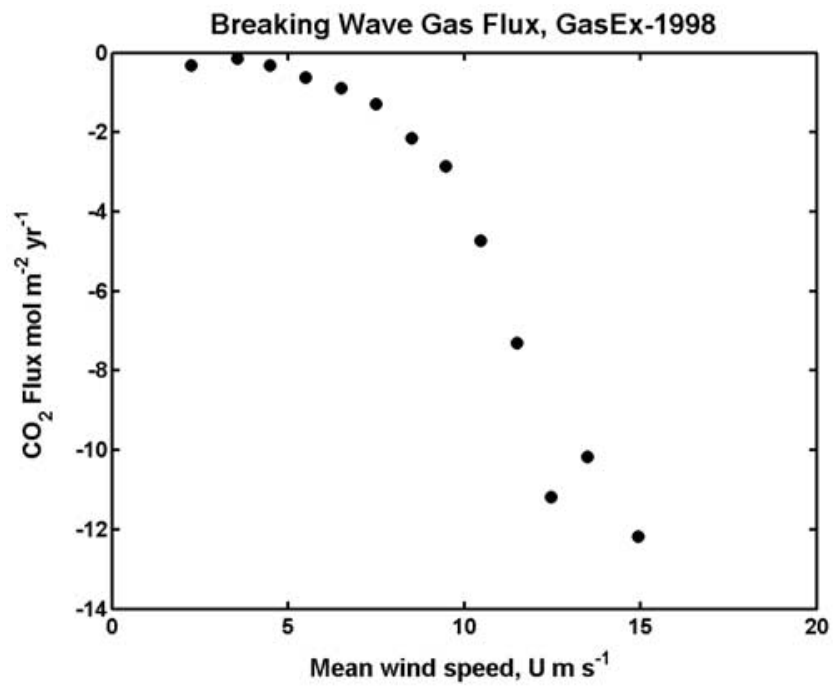

Figure 5. Contribution to the GasEx-1998 air-sea $\mathrm{CO}_{2}$ flux by breaking wave processes, obtained by subtraction of the modeled interfacial flux $\left(\boldsymbol{k}_{\boldsymbol{b}}=0\right)$ from the directly measured flux. 


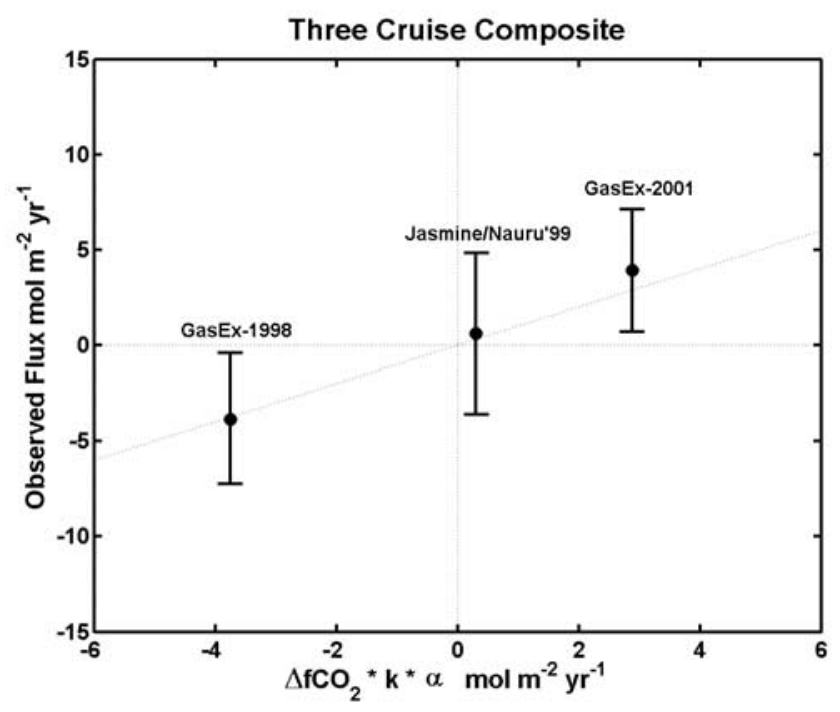

Figure 6. Composite averages and standard deviations of the fluxes from three deployments of the gas flux instrumentation aboard the NOAA ship Ronald H. Brown plotted versus measured air-sea fugacity difference times the parameterized transfer velocity and solubility.

1998, it was determined that the bias in the fluxes due to ship motion for low wave states was approximately $2 \mathrm{~mol} \mathrm{~m}^{-2} \mathrm{yr}^{-1}$, and this factor was subtracted from the resulting flux estimates [McGillis et al., 2001a, Figure 2b]. It is expected that there are wave state dependencies of the ship motion effect on the NDIR instrument, but the simple constant bias was assumed for this exercise. Because of the ubiquitous light winds and low fluxes encountered during this deployment, we will only report the composite averaged flux here.

[43] In Figure 6, we show the composite mean and standard deviation of the fluxes from the three deployments (GasEx-1998, JASMINE/Nauru99, and GasEx-2001). In fact, these error estimates were computed from the difference between the measured flux and the modeled flux in order to remove the wind speed dependence from the composites. Standard errors were also computed, but the resulting plot was less then the size of the mean data circles shown in Figure 6 . The means of the measured fluxes are plotted against $\Delta \boldsymbol{f C O}_{2}{ }^{*} \boldsymbol{k}^{*} \boldsymbol{\alpha}$, which is similar in structure to equation (8). This plot shows the bias in the mean flux results which are well within the standard deviation of each sample. Note that the GasEx-2001 results show a small bias of order $1 \mathrm{~mol} \mathrm{~m}^{-2} \mathrm{yr}^{-1}$, and it is reasonable to expect that this bias may be explained through the arguments made earlier in section 5.1 or by a systematic bias error in the covariance measurements. A very small bias remains in the JASMINE/Nauru'99 composite, but it is encouraging that the mean flux lies very close to the 1:1 line as shown. In addition, the JASMINE/Nauru'99 results show that it is possible (albeit difficult) to make direct covariance carbon dioxide flux measurements in low flux regimes.

\subsection{Parameterizations of the Normalized Gas Transfer Velocity}

[44] As a final demonstration of the results, the wind speed bin average parameterized GasEx-1998 and GasEx-
2001 gas transfer velocities are shown in Figure 7, plotted against the $10 \mathrm{~m}$ neutral stability wind speed. These values of $\boldsymbol{k}$ are normalized to a Schmidt number of 660, which is a standard practice in the gas transfer literature. In addition, we have plotted some of the proposed wind speed based parameterizations of the gas transfer velocity from Wanninkhof [1992], Wanninkhof and McGillis [1999], and Liss and Merlivat [1986].

[45] As can be seen in this figure, the parameterized transfer velocities collapse onto one curve. This is not unexpected, since the Schmidt number normalization correction effectively removes differences in gas diffusivity and because the NOAA/COARE model is only mildly dependent on the difference in the observed surface net heat flux for the two data sets. This is also an indication of the relative insensitivity of the model to the averaged buoyant processes for these particular data sets. As expected, the parameterized values of $\boldsymbol{k}$ closely resemble the cubic wind speed relationship of Wanninkhof and McGillis [1999], since both results have been adjusted to the GasEx-1998 data set.

\section{Conclusions}

[46] The NOAA/COARE gas flux parameterization was run using the GasEx-1998 and GasEx-2001 experimental data sets including the warm layer and cool skin parameterizations from the COARE bulk algorithm code. Coincident directly measured fluxes from GasEx-1998 were compared to the NOAA/COARE parameterization output, and the model was tuned to this data set. This tuning process required significant adjustment (factor of 2) to the Woolf [1997] coefficient and also required that the Soloviev and Schlüssel [1994] constant be adjusted by a

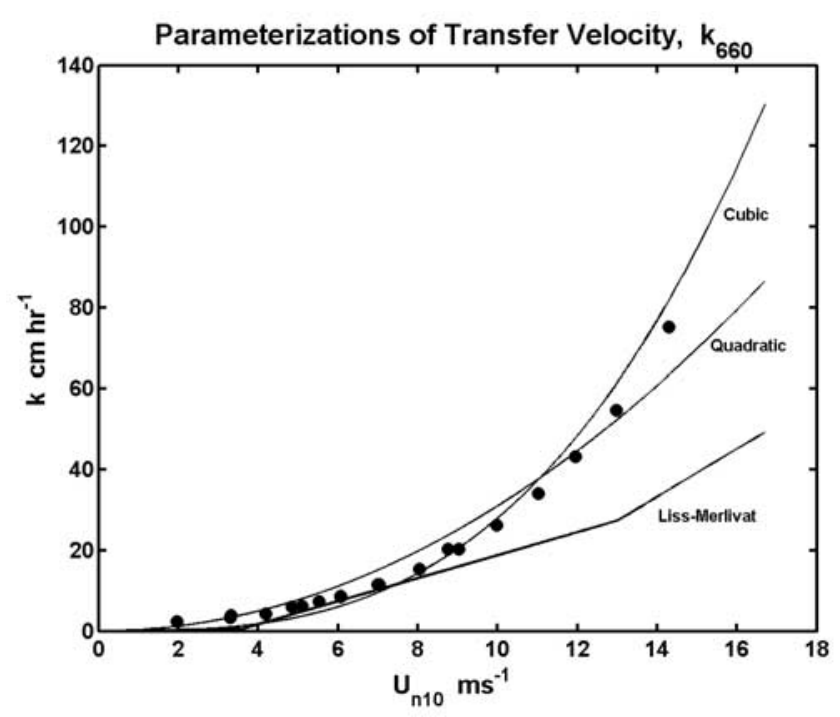

Figure 7. Plot of the wind speed bin-averaged GasEx parameterized transfer velocities, normalized to a Schmidt number of 660 , versus the $10 \mathrm{~m}$ neutral wind speed. Also plotted are three representative wind speed only parameterizations of transfer velocity from Wanninkhof [1992], Wanninkhof and McGillis [1999], and Liss and Merlivat [1986]. 
factor of three. Comparison of the wind speed bin-averaged flux values from the model and the directly measured fluxes yielded a good fit for the GasEx-1998 data, while some significant differences were seen from the GasEx-2001 flux results. These differences could be due to systematic bias in the direct covariance $\mathrm{CO}_{2}$ flux measurements between the two cruises, to complications from biological processes and surfactants, or as a result of poor model characterization of the oceanic mixed layer processes for the two distinct experimental regimes. There may also be some unforeseen effect resulting from the fact that the gas transfer acts in opposing directions (upward flux for GasEx-2001 and downward gas flux for GasEx-1998) for the two cases. It is seen that the GasEx-2001 results show relatively larger interfacial fluxes, while the wave-breaking and bubble processes are weaker.

[47] The most significant finding of this work is the estimation of the relative magnitude of the gas transfer which is due to higher wind, breaking wave processes as opposed to interfacial exchange. This estimate was made by comparing the GasEx-1998 measured $\mathrm{CO}_{2}$ fluxes against the NOAA/COARE model output. It was seen in Figure 5 that $80 \%$ of the flux at moderate wind speeds occurred because of bubbles and wave breaking, which has clear implications for accurately modeling carbon dioxide fluxes at the higher wind speed regimes.

[48] There are complex processes occurring in the oceanic surface layer, including biological activity, surfactants, wave breaking and bubbles, etc. It is expected that these processes play a significant role in gas exchange, but considerable progress remains to be made in order to accommodate more appropriate parameterizations of these effects into the model. It is anticipated that progress in all aspects of gas exchange may contribute to the improvement of the parameterization in the future. Significant progress on the NOAA/COARE algorithm may also be possible through inclusion of a biological model. Because of the significant flux which occurs at high winds, it is also important that progress be made in parameterizing the transfer coefficient over breaking waves. In addition, focused process studies of gas exchange with coincident measurements of $\mathrm{CO}_{2}$ flux and all other relevant physical and biological processes will continue to provide vital details which can be incorporated into the model.

[49] Acknowledgments. This work was supported by the NOAA Office of Global Programs, under the leadership of Dr. Lisa Dilling. WHOI was supported by the National Science Foundation grant OCE-9711218. We wish to thank the officers and crew of the NOAA ship Ronald H. Brown for their usual outstanding support and professionalism. Additional thanks are due to Robert Castle from NOAA/AOML for the maintenance and continued development of the underway $\mathrm{fCO}_{2}$ system on the Brown, to Jonathan Ware for the development of the WHOI closed path atmospheric $\mathrm{CO}_{2}$ measurement system, and to the NOAA/ETL and CU/CIRES engineering staff: Scott Abbott, Jesse Leach, David Costa, Sergio Pezoa, and Brian Templeman.

\section{References}

Asher, W., and R. Wanninkhof (1998), Transient tracers and air-sea gas transfer, J. Geophys. Res., 103, 15,939-15,958.

Bock, E. J., T. Hara, N. M. Frew, and W. R. McGillis (1999), Relationship between air-sea gas transfer and short wind waves, J. Geophys. Res., 104, $25,821-25,831$
Broecker, W. S., and T.-H. Peng (1974), Gas exchange rates between air and sea, Tellus, 24, 21-35.

Broecker, W. S., J. R. Ledwell, T. Takahashi, L. M. R. Weiss, L. Memery, T.-H. Peng, B. Jahne, and K. O. Münnich (1986), Isotopic versus micrometeorological ocean $\mathrm{CO}_{2}$ fluxes: A serious conflict, J. Geophys. Res., $91,10,517-10,527$

Edson, J. B., A. A. Hinton, K. E. Prada, J. E. Hare, and C. W. Fairall (1998), Direct covariance flux estimates from mobile platforms at sea, J. Atmos. Oceanic Technol., 15, 547-562.

Fairall, C. W., E. F. Bradley, J. S. Godfrey, G. A. Wick, J. B. Edson, and G. S. Young (1996a), Cool-skin and warm-layer effects on sea surface temperature, J. Geophys. Res., 101, 1295-1309.

Fairall, C. W., E. F. Bradley, D. P. Rogers, J. B. Edson, and G. S. Young (1996b), Bulk parameterization of air-sea fluxes for TOGA-COARE, J. Geophys. Res., 101, 3747-3764.

Fairall, C. W., J. E. Hare, J. B. Edson, and W. McGillis (2000), Parameterization and micrometeorological measurements of air-sea gas transfer, Boundary Layer Meteorol., 96, 63-105.

Frew, N. M. (1997), The role of organics films in air-sea gas exchange, in The Sea Surface and Global Change, edited by R. Duce and P. Liss, pp. 121-172, Cambridge Univ. Press, New York.

Hare, J. E., C. W. Fairall, W. R. McGillis, B. Ward, and R. Wanninkhof (2003), Temperature sensitivity of a micrometeorologically-based air sea gas transfer parameterization, paper presented at 12th Conference on Interactions of the Sea and Atmosphere, Am. Meteorol. Soc., Long Beach, Calif.

Jähne, B., K. O. Münnich, R. Bösinger, A. Dutzi, W. Huber, and P. Libner (1987), On the parameters influencing air-water gas exchange, J. Geophys. Res., 92, 1937-1949.

Janssen, P. A. E. M. (1999), On the effect of ocean waves on the kinetic energy balance and consequences for the inertial dissipation technique, J. Phys. Oceanogr., 29, 530-534.

Kanwisher, J. (1963), On the exchange of gases between the atmosphere and the sea, Deep Sea Res., 10, 195-207.

Law, D. C., S. A. McLaughlin, M. J. Post, B. L. Weber, D. C. Welsh, D. E. Wolfe, and D. E. Merritt (2002), An electronically stabilized phased array system for shipborne atmospheric wind profiling, J. Atmos. Oceanic Technol., 19, 924-933.

Liss, P. S., and L. Merlivat (1986), Air-sea gas exchange rates: Introduction and synthesis, in The Role of Air-Sea Exchange in Geochemical Cycles, edited by P. Buat-Manard, pp. 113-127, D. Reidel, Norwell, Mass.

McGillis, W. R., J. B. Edson, J. E. Hare, and C. W. Fairall (2001a), Direct covariance air-sea $\mathrm{CO}_{2}$ fluxes, J. Geophys. Res., 106, 16,72916,745 .

McGillis, W. R., J. B. Edson, J. D. Ware, J. W. H. Dacey, J. E. Hare, C. W. Fairall, and R. Wanninkhof (2001b), Carbon dioxide flux techniques performed during GasEx-98, Mar. Chem., 75, 267280

Monahan, E. C., and I. O'Muircheartaigh (1980), Optimal power-law description of oceanic whitecap coverage dependence on wind speed, J. Phys. Oceanogr. Res., 10, 2094-2099.

O'Muircheartaigh, I., and E. C. Monahan (1986), Statistical aspects of the relationship between oceanic whitecap coverage, wind speed, and other environmental factors, in Oceanic Whitecaps, edited by E. C. Monahan and G. M. Niocaill, pp. 125-128, D. Reidel, Norwell, Mass.

Siegel, D. A., S. Maritorena, N. B. Nelson, D. A. Hansell, and M. LorenziKayser (2002), Global distribution and dynamics of colored dissolved and detrital organic materials, J. Geophys. Res., 107(C12), 3228, doi:10.1029/2001JC000965.

Smith, S. D., and E. P. Jones (1985), Evidence for wind-pumping of air-sea exchange based on direct measurements of $\mathrm{CO}_{2}$ fluxes, J. Geophys. Res., $90,869-875$.

Soloviev, A. V., and P. Schlüssel (1994), Parameterization of the cool skin of the ocean and of the air-ocean gas transfer on the basis of modeling surface renewal, J. Phys. Oceanogr., 24, 1339-1346.

Spillane, M. C., E. C. Monahan, P. A. Bowyer, D. M. Doyle, and P. J. Stabeno (1986), Whitecaps and global fluxes, in Oceanic Whitecaps and Their Role in Air-Sea Exchange Processes, edited by E. Monahan and C. MacNiocaill, pp. 209-218, D. Reidel, Norwell, Mass.

Strutton, P. G., F. P. Chavez, R. C. Dugdale, and V. Hogue (2004), Primary productivity in the central equatorial Pacific $\left(3^{\circ} \mathrm{S} 130^{\circ} \mathrm{W}\right)$ during GasEx2001, J. Geophys. Res., 109, C08S06, doi:10.1029/2003JC001790, in press.

Takahashi, T., J. Olafsson, J. G. Goddard, D. W. Chipman, and S. C. Sutherland (1993), Seasonal variations of $\mathrm{CO}_{2}$ and nutrients in the high-latitude surface oceans: A comparative study, Global Biogeochem. Cycles, 7, 843-878. 
Terray, E. A., M. A. Donelan, Y. C. Agrawal, W. M. Drennan, K. K Kahma, A. J. Williams, P. A. Hwang, and S. A. Kitaigorodskii (1996) Estimates of kinetic energy dissipation under breaking waves, J. Phys. Oceanogr., 26, 792-807.

Wanninkhof, R. (1992), Relationship between wind speed and gas exchange over the ocean, J. Geophys. Res., 97, 7373-7382.

Wanninkhof, R., and W. R. McGillis (1999), A cubic relationship between air-sea $\mathrm{CO}_{2}$ exchange and wind speed, Geophys. Res. Lett., 26, 1889 1892.

Wanninkhof, R., and K. Thoning (1993), Measurement of fugacity of $\mathrm{CO}_{2}$ in surface water using continuous and discrete sampling methods, Mar. Chem., 44, 189-204.

Ward, B., R. Wanninkhof, W. R. McGillis, A. T. Jessup, M. D. DeGrandpre, J. E. Hare, and J. B. Edson (2004), Biases in the air-sea flux of $\mathrm{CO}_{2}$ resulting from ocean surface temperature gradients, J. Geophys. Res., 109, C08S08, doi:10.1029/2003JC001800.

Weiss, R. F. (1974), Carbon dioxide in water and seawater: The solubility of a nonideal gas, Mar. Chem., 2, 203-215.
Woolf, D. K. (1997), Bubbles and their role in gas exchange, in The Sea Surface and Global Change, edited by R. Duce and P. Liss, pp. 173-205, Cambridge Univ. Press, New York.

J. B. Edson, W. R. McGillis, and B. Ward, Department of Applied Ocean Physics and Engineering, Woods Hole Oceanographic Institution, Woods Hole, MA 02543, USA. (jedson@whoi.edu; wmcgillis@whoi.edu; bward@whoi.edu)

C. W. Fairall, Clouds, Radiation, and Surface Processes Division, NOAA Environmental Technology Laboratory, 325 Broadway, Boulder, CO 80305, USA. (chris.fairall@noaa.gov)

J. E. Hare, Cooperative Institute for Research in Environmental Sciences, University of Colorado, Campus Box 216, Boulder, CO 80309, USA. (jeffrey.hare@colorado.edu)

R. Wanninkhof, Ocean Chemistry Division, NOAA Atlantic Oceanographic and Meteorological Laboratory, 4301 Rickenbacker Causeway, Miami, FL 33149, USA. (rik.wanninkhof@noaa.gov) 